\title{
Influence of Basic Psychological Needs over Burnout in the Sport Context
}

\author{
María Del Pilar Vílchez Conesa ${ }^{1, *} \mathbb{*}$, Francisco Parra Plaza ${ }^{1, * \mathbb{D}}$, Constantino Arce ${ }^{2}$ \\ and Cristina De Francisco ${ }^{3}$ (D) \\ 1 Faculty of Social Sciences and Communication, Catholic University of Murcia, 30107 Murcia, Spain \\ 2 Department of Social and Basic Psychology and Methodology, University of Santiago de Compostela, \\ 15782 Santiago de Compostela, Spain; constantino.arce@usc.es \\ 3 Faculty of Health Sciences, Catholic University of Murcia, 30107 Murcia, Spain; cdefrancisco@ucam.edu \\ * Correspondence: mdpvilchez@ucam.edu (M.D.P.V.C.); fjpplaza@ucam.edu (F.P.P.)
}

Received: 13 July 2020; Accepted: 5 August 2020; Published: 7 August 2020

\begin{abstract}
The aim of this study was to investigate the relationship among basic psychological needs and burnout in a sample of athletes $(\mathrm{N}=639)$. It was hypothesized that psychological needs satisfaction was negatively associated with burnout syndrome and the frustration of these needs related positively. Burnout was measured with the Athlete Burnout Questionnaire (ABQ), satisfaction of basic psychological needs with the Basic Needs Satisfaction in Sport Scale (BNSSS), and frustration with the Psychological Needs Thwarting Scale (PNTS). Data analysis was conducted under the approach of structural equation modeling (SEM). The results showed that satisfaction of basic psychological needs had a negative direct effect on burnout of $-0.67(p<0.001)$ while the frustration of these needs had a direct effect of $0.18(p<0.001)$. In addition, the total model explained $59 \%$ of the total variance of burnout. All individual parameters of the model were statistically significant and the overall fit of the model was satisfactory. It can be concluded that satisfying the basic psychological needs of the athletes can protect them against burnout.
\end{abstract}

Keywords: burnout; basic psychological needs; athletes

\section{Introduction}

Athlete burnout is a research topic that has been on the rise for last decade [1]. This syndrome affects athletes and is characterized by the presence of three dimensions [2]. First, it establishes that athletes not only suffer physical exhaustion associated with both training and competition, but they also have emotional exhaustion derived from demands required by their sports modality (e.g., an athlete with a high training load will also have emotional exhaustion). Second, sport devaluation implies deterioration and negative attitudes toward the sport (e.g., the participation could go down). Third, reduced sense of accomplishment, in sporting terms, refers to the difficulty of achieving proposed sports goals (e.g., an athlete who has a high participation in sports events and does not reach his desired mark).

There are different theories that explain the etiology of this syndrome are different, like the basic psychological needs theory (BPNT) [3]. The BPNT highlights the existence of three psychological needs considered basic for the human well-being (competence, autonomy, and relatedness), which must be met to achieve an optimum psychological development and personal well-being. The competence is the capacity of an athlete to experience mastery and effectiveness in their sports skills, in addition to being able to perform tasks of different levels of difficulty. The need for autonomy refers to the need for an athlete to act for their own interests and values while feeling involved in a sports activity. In an athlete, you can appreciate the need for a relatedness when he is able to feel linked, supported, 
or loved by other people involved in his sports environment. The degree to which these psychological needs in athletes are satisfied is related to positive psychological consequences, and when such needs are frustrated, they tend to be related to negative consequences such as with burnout syndrome $[4,5]$. In addition, the frustration of needs composes the central element in the negative consequences that affect the personal environment [6]. In the sports context, several studies have related the basic psychological needs with the psychological states experienced by athletes [7-10].

Researching about origin of athlete burnout, many studies are related to self-determination theory (SDT) from the perspective of the regulations of behavior [11]. Specifically, how the last degree of self-determined motivation, that is, demotivation, has a strong association with the syndrome of burnout as well as how intrinsic motivation has a negative relation with this syndrome [2].

Initially, it was demonstrated through different interviews that those athletes who presented a higher degree of burnout also had higher levels of demotivation when compared to athletes who had a lower degree of burnout [12]. Although, athletes who have less self-determined motivation seem to increases the risk of suffering burnout, but other authors believe that the relationship is not sufficiently consistent because of its lower influence [13].

However, the connection between BPNT and the explanation of the origins of burnout has been confirmed [14,15]. Studies revealed that greater satisfaction in the psychological needs of athletes was related to low levels of burnout $[4,16]$, as well as a positive relationship between burnout and frustration of basic psychological needs [6]. The obstruction in the satisfaction of psychological needs can generate an increased risk of suffering from burnout and reduced commitment to sport in the athlete [8]. Additionally, the effect of basic psychological needs has been observed on burnout. Jowett et al. [8] concluded that basic psychological needs have relationships between perfectionism and burnout, using a structural equation modeling. Specifically, the frustration of basic psychological needs had a direct effect on burnout of 0.47 and the satisfaction basic psychological need had a negative direct effect on burnout of -0.34 . As well, the effect of the frustration of the basic psychological needs and burnout was also observed [7,9], where the frustration of basic psychological needs had a positive and significant effect on athlete burnout of 0.59 [9] and 0.57 [7]. On the other hand, within BPNT, there are studies that point out the importance of support in the satisfaction of autonomy in athletes and their relationship with positive consequences, and how the frustration of them can generate negative consequences [17]. Specifically, investigations have highlighted how autonomy may be the dimension that links to burnout due to its close affinity with intrinsic motivation [14].

It is necessary to consider that BPNT states that satisfaction and frustration of basic psychological needs function as a unified concept [15]. However, recently it has been shown that both the satisfaction and the frustration of needs are not psychometric opposites, and also present an independent functioning [18]. In addition, the fact that an athlete is not sad does not mean that he feeling cheerful; not feeling competent during a sports competition does not make an athlete feel useless, and that if the link between an athlete with his teammates is not totally good does not mean that it is bad. Regarding this differentiation, Longo, Alcaráz-Ibáñez and Sicilia [19] specified that items used to assess satisfaction and frustration of a psychological need do not always converge, so their usefulness for research is being limited. They also indicated that they have a better fit when treated separately, rather than a single concept, as done in the present study. There are different works that deal with the meaning of the items that evaluate satisfaction and frustration, in which the frustration of psychological needs evaluates in a different way what can take into account low levels of satisfaction [20]. Previous studies indicate that frustration predicts "why" a need is not satisfied, however, satisfaction may not have the potential to do it. In addition, Sheldon [20] observed how the satisfaction of needs has been modified over time, while the frustration remained intact, presenting independent indexes of behavior they had. Vansteenkiste and Ryan [21] stated that the relationship between satisfaction and frustration of needs was asymmetric, because there may be low satisfaction but not necessarily frustration of needs, and yet the term frustration implies low satisfaction. They also affirmed that the low satisfaction of a need is not strongly related to ill-being, but it can generate long-term problems while the process 
of deterioration in discomfort accelerates when a need is suddenly frustrated. In fact, this statement is stronger when observing studies in which it has been shown that the need for satisfaction and frustration have different relationships with external variables, with the need for satisfaction more strongly related to well-being and the need for frustration more strongly related to ill-being [19].

Another key aspect to consider in the present study refers to dimensions of BPNS. The work of [22] identified a new underlying dimension for autonomy, which implies the ability to act voluntarily; choosing or making decisions that the athlete considers to be correct; and having the ability to know how to direct their conduct every time. Therefore, the tool used in this study allows an evaluation of these identified sub-dimensions [23], contributing a more complete perspective from the point of view of this theory.

There is a recent interest in burnout and its evolution over the years and its attempt to reduce its occurrence [24,25], and this study offers other perspectives of the theory. Few evidences have been shown so far that speak about the relationships between BPN satisfaction and burnout, but it is needed to use all autonomy subdimensions, taking into account that BPN frustration should be treated as a concept independent of satisfaction. For that reason, the present study uses an original description of these relationships in order to offer empirical support to the theories that give rise to this syndrome.

Therefore, given the evidence of basic psychological needs satisfaction can have a direct effect on sport burnout, that, in turn, has a greater direct effect the frustration of needs over this syndrome. The main purpose of this work was to obtain a better understanding of the nature of the autonomy construct taking into account the identification of three subscales, to confirm the relationship between the BPNT and burnout. Another objective was to observe the negative effect when treating BPN as independent constructs but simultaneously, taking into account that satisfaction and frustration of needs are two distinguishable concepts but, at the same time, they are related.

\section{Method}

\subsection{Participants}

This study was carried out with an intentional non-probabilistic sample consisting of 639 athletes from different individual sports $(n=200)$ and team sports $(n=439)$. The age of the study participants was between 13 and 56 years $(M=18.78, S D=5.94)$. A total of $58.7 \%$ of the athletes were minors and $41.3 \%$ were adults. Men comprised $48.4 \%$ and $51.6 \%$ were women. The highest percentage of participation in terms of modality of sport was in football (49\%), followed by athletics (10.6\%). A total of $36.8 \%$ of the athletes had a low competitive profile (local/regional categories) and $63.2 \%$ had a high competitive profile (regional and national categories). The mean of weekly training was 3.35 sessions $(\mathrm{SD}=1.22)$, with a mean of duration of $99.36 \mathrm{~min}$ per session $(\mathrm{SD}=21.27)$.

\subsection{Instruments}

The Spanish version of the Athlete Burnout Questionnaire (ABQ) [26] was used to evaluate the burnout levels in athletes. The ABQ is formed by 15 items: five items for the physical and emotional exhaustion dimension (PEE), five items for reduced sense of accomplishment (RSA), and five items in sport devaluation (D). This questionnaire offered a Likert scale response that went from (1) "Almost never" to (5) "Almost always". The numerical value refers to the highest response value, except for items 1, 5, 7, and 14 (for example, “In the [sport] I am getting many things that are worthwhile."), where the reduced sense of accomplishment were formulated in reverse (the highest numerical value indicates the lowest degree of burnout).

The Spanish version of the Basic Needs Satisfaction in Sport Scale instrument (BNSSS) [27] was used to assess the satisfaction of BPN in athletes. This scale consists of 20 items, five items for the measurement of the competence dimension, 10 items for the autonomy dimension, and five items for the relatedness dimension. The dimension autonomy is divided in turn into four items for autonomy choice (ACho) and three items for each of the dimensions of autonomy volition (AVol) and autonomy 
internal perceived locus of causality (ALoc). The BNSSS presents a Likert response from (1) "Nothing true" to (7) "Totally true". The highest numerical value refers to the highest response value, except for the fifth item ("In [sport], I feel compelled to do things I do not want to do"; autonomy volition) which was formulated in reverse (the highest numerical value indicates the lowest degree of satisfaction).

Finally, the Spanish version of the Psychological Needs Thwarting Scale (PNTS) [28] was used to evaluate the frustration of BPN in the sport context. This scale is formed by 12 items, four for each dimension of competence (COM), autonomy (AUT), and relatedness (REL). This scale has a Likert type response format that ranges from (1) "Strongly Disagree" to (7) "Strongly Agree". The highest numerical value corresponds with the highest degree of frustration. ("I feel incompetent because they have not given me the opportunity to develop my potential"; competence).

\subsection{Procedure}

First, authorization was requested from the university's ethics committee of the research team. Subsequently, the heads of sports clubs and coaches were contacted to specify availability in the administration of the questionnaires. Once the appointment was made, researchers went to the high-performance centers or usual training places of each team/athlete to administer the questionnaires. This was all carried out during the 15 min prior to the usual training session, five minutes for explanations and $10 \mathrm{~min}$ to fill in the instrument. All this was done in order not to affect the training time programmed by their coach for that day. Prior to completing the questionnaires, participants were informed of the objective of study and how to respond to it, and all athletes (or the sports tutor in the case of minors) had signed an informed consent form and were approved to participate in the research. Each athlete completed the questionnaire privately and individually, generally separate from the training group. The data collection process lasted two years and was carried out throughout a competitive season for each sport modality.

\subsection{Data Analysis}

Exploratory data analysis was performed which allowed the researchers to verify that there were no answers out of range or missing values in any of the observed variables. Descriptive statistics were calculated using the statistical package SPSS 21 (IBM Statistics). Finally, a structural equation modeling (SEM) approach was used to test the hypothesized model by using Amos Graphics 21 (IBM Statistics).

An invariance analysis was also carried out, based on to three nested models to check the equality of model between individual and collective sports modalities. The model shows indicators of non-variability (CFI $>0.01)$.

\section{Results}

\subsection{Descriptive Statistics}

Tables 1-3 provide the descriptive statistics (mean, standard deviation, skewness, and kurtosis) for each of the items and dimensions of ABQ, BNSSS, and PNTS.

For burnout (Table 1), items means were located between $1.38(\mathrm{SD}=0.84, \mathrm{D} 5)$ and $2.85(\mathrm{SD}=1.05$, RSA 5). The range of standard deviations was found between 0.83 (D 1) and 1.25 (D 4). Regarding the distribution of the data, all items showed a positive skewness, with items D 1 and 5 having the highest values (2.53 and 1.96, respectively). Finally, the kurtosis index reached the highest value in D 5 (6.15). Regarding the dimensions, the highest mean was located in reduced sense of accomplishment $(2.32 ; \mathrm{SD}=0.71)$ and the lowest was sport devaluation $(1.65, \mathrm{SD}=0.75)$.

In the BNSSS (Table 2), means of the items were between $4.70(\mathrm{SD}=1.71, \mathrm{ACho} 2)$ and 6.50 $(\mathrm{SD}=1.05, \mathrm{Avol} 3)$. The standard deviations were found to range between $1.05(\mathrm{AVol} \mathrm{3})$ and 1.71 (ACho 2). With regards to the distribution of the data, all items showed a negative skewness, with relatedness items 4 and 5 having the highest values ( -2.21 and -1.72 , respectively). Finally, the kurtosis 
index indicated the highest value in Avol 3 (7.93). For the dimensions, the highest mean was located in $\mathrm{AVol}(6.12, \mathrm{SD}=1.02)$ and the lowest was ACho $(5.06, \mathrm{SD}=1.24)$.

Table 1. Descriptive statistics for the items and subscales of the Athlete Burnout Questionnaire (ABQ).

\begin{tabular}{ccccc}
\hline Items & Mean & Standard Deviation & Skewness & Kurtosis \\
\hline PEE 1 & 2.75 & 0.96 & 0.13 & -0.24 \\
PEE 2 & 1.95 & 0.96 & 0.93 & 0.50 \\
PEE 3 & 2.15 & 1.10 & 0.72 & -0.26 \\
PEE 4 & 2.06 & 1.06 & 0.83 & 0.04 \\
PEE 4 & 1.99 & 0.93 & 0.77 & 0.36 \\
\hline RSA 1 & 1.90 & 0.88 & 0.83 & 0.40 \\
RSA 2 & 2.40 & 1.03 & 0.41 & -0.35 \\
RSA 3 & 2.34 & 1.07 & 0.49 & -0.37 \\
RSA 4 & 2.10 & 1.06 & 0.71 & -0.20 \\
RSA 5 & 2.85 & 1.05 & 0.21 & -0.45 \\
\hline D 1 & 1.45 & 0.83 & 1.96 & 3.40 \\
D 2 & 1.78 & 1.14 & 1.39 & 0.96 \\
D 3 & 1.56 & 0.99 & 1.79 & 2.34 \\
D 4 & 2.07 & 1.25 & 0.94 & -0.22 \\
D 5 & 1.38 & 0.84 & 2.53 & 6.15 \\
\hline PEE & 2.18 & 0.77 & 0.54 & -0.04 \\
RSA & 2.32 & 0.71 & 0.39 & -0.02 \\
D & 1.65 & 0.75 & 1.63 & 2.24 \\
\hline
\end{tabular}

Note. PEE: physical and emotional exhaustion; RSA: reduced sense of accomplishment; D: sport devaluation.

Table 2. Descriptive statistics for the items and subscales of the Basic Needs Satisfaction in Sport Scale (BNSSS).

\begin{tabular}{ccccc}
\hline Items & Mean & Standard Deviation & Skewness & Kurtosis \\
\hline COM 1 & 5.70 & 1.30 & -1.12 & 0.92 \\
COM 2 & 5.86 & 1.22 & -1.20 & 1.41 \\
COM 3 & 5.47 & 1.35 & -0.85 & 0.23 \\
COM 4 & 5.44 & 1.40 & -0.90 & 0.38 \\
COM 5 & 5.64 & 1.31 & -1.03 & 0.69 \\
\hline ACho 1 & 5.31 & 1.48 & -0.84 & 0.33 \\
ACho 2 & 4.70 & 1.71 & -0.54 & -0.49 \\
ACho 3 & 4.97 & 1.59 & -0.66 & -0.23 \\
ACho 4 & 5.30 & 1.54 & -0.94 & 0.40 \\
\hline AVol 1 & 5.98 & 1.29 & -1.33 & 1.14 \\
AVol 2 & 5.90 & 1.66 & -1.52 & 1.25 \\
AVol 3 & 6.50 & 1.05 & -2.70 & 7.93 \\
\hline ALoc 1 & 5.56 & 1.48 & -1.12 & 0.78 \\
ALoc 2 & 5.74 & 1.37 & -1.05 & 0.43 \\
ALoc 3 & 6.09 & 1.26 & -1.59 & 2.19 \\
\hline REL 1 & 6.09 & 1.29 & -1.59 & 2.14 \\
REL 2 & 5.59 & 1.53 & -1.21 & 0.96 \\
REL 3 & 5.97 & 1.31 & -1.43 & -1.69 \\
REL 4 & 6.15 & 1.20 & -1.72 & 2.92 \\
REL 5 & 6.33 & 1.13 & -2.21 & 5.17 \\
\hline COM & 5.62 & 1.07 & -0.92 & 0.58 \\
ACho & 5.06 & 1.24 & -0.66 & 0.05 \\
AVol & 6.12 & 1.02 & -1.32 & 1.22 \\
ALoc & 5.79 & 1.12 & -1.12 & 1.03 \\
REL & 6.02 & 0.97 & -1.33 & 1.58 \\
\hline
\end{tabular}

Note. COM: competence; ACho: autonomy choice; AVol: autonomy volition; ALoc:autonomy internal perceived locus of causality; REL: relatedness. 
Table 3. Descriptive statistics for the items and subscales of Psychological Needs Thwarting Scale (PNTS).

\begin{tabular}{ccccc}
\hline Items & Mean & Standard Deviation & Skewness & Kurtosis \\
\hline COM 1 & 2.37 & 1.58 & 1.00 & -0.00 \\
COM 2 & 2.32 & 1.65 & 1.22 & 0.60 \\
COM 3 & 2.42 & 1.63 & 1.09 & 0.24 \\
COM 4 & 2.04 & 1.59 & 1.60 & 1.68 \\
\hline AUT 1 & 2.35 & 1.64 & 1.12 & 0.33 \\
AUT 2 & 1.91 & 1.39 & 1.64 & 2.05 \\
AUT 3 & 2.01 & 1.51 & 1.65 & 1.98 \\
AUT 4 & 2.13 & 1.53 & 1.35 & 0.97 \\
\hline REL 1 & 1.64 & 1.31 & 2.43 & 5.51 \\
REL 2 & 2.04 & 1.56 & 1.58 & 1.66 \\
REL 3 & 2.02 & 1.54 & 1.71 & 2.14 \\
REL 4 & 2.11 & 1.73 & 1.59 & 1.42 \\
\hline COM & 2.28 & 1.27 & 1.06 & 0.59 \\
AUT & 2.10 & 1.20 & 1.42 & 2.11 \\
REL & 1.95 & 1.25 & 1.63 & 2.49 \\
\hline
\end{tabular}

Note. COM: competence; AUT: autonomy; REL: relatedness.

For the PNTS (Table 3), means were located between 1.64 (SD = 1.31, REL 1) and $2.42(\mathrm{SD}=1.63$, COM 3). The standard deviations ranged from 1.31 (REL 1) and 1.73 (REL 4). In addition, all items showed a positive skewness, with REL 1 and 3 presenting the highest values (2.43 and 1.71, respectively). The highest value for the kurtosis index was reached in REL 1 (5.51). Regarding the dimensions, the highest mean was located in COM $(2.28, \mathrm{SD}=1.27)$ and the lowest was REL $(1.95, \mathrm{SD}=1.25)$.

\subsection{Structural Equation Modeling (SEM)}

The specified SEM model is shown in Figure 1, which was comprised of three multifactor measurement submodels and the structural relationships that originated between them. The satisfaction of basic psychological needs (SBPN), the frustration of psychological needs (FBPN) and burnout were endogenous variables, since they contained a residual error. In this model, the SBPN and FBPN, in combination, had a direct effect on burnout. In addition, all of the observed variables (items of the questionnaires) contained an error term.

This specified model contained 1128 different sample moments, 118 parameters to estimate, and 1010 degrees of freedom. The method used to estimate the parameters was the maximum likelihood (ML) with bootstrap because of multivariate non normal distribution (Mardia's coefficient $=673.408$; $\mathrm{CR}=125.41)$.

The overall model fit was $\chi^{2}(1007)=3020.558(p<0.001) ; \chi^{2} / \mathrm{df}=2.99$; goodness of fit index $(\mathrm{GFI})=0.81$; comparative fit index $(\mathrm{CFI})=0.86$; root mean square error of approximation $($ RMSEA $)=0.056(90 \%$ confidence interval, $0.054-0.058)$; and root mean square residual $($ SMSR $)=0.07$. In addition, all of the factor loadings were statistically significant $(p<0.01)$ as well as the variances of the errors (e1, e2, .. , e47), the residuals (res1, res2, . , res13), and the direct effects in the expected direction under hypothesis.

The satisfaction of basic psychological needs had a direct effect on burnout of $-0.67(p<0.001)$ and the frustration of these needs had an effect of $0.18(p<0.001)$. In addition, the total explained variance of burnout was $59 \%\left(R^{2}=0.59 ; p<0.01\right)$. Table 4 provides the values of $\lambda$ (factor loadings), $\delta(1-\lambda 2)$, and percentages of variance explained for each item $\left(R^{2}\right)$. 


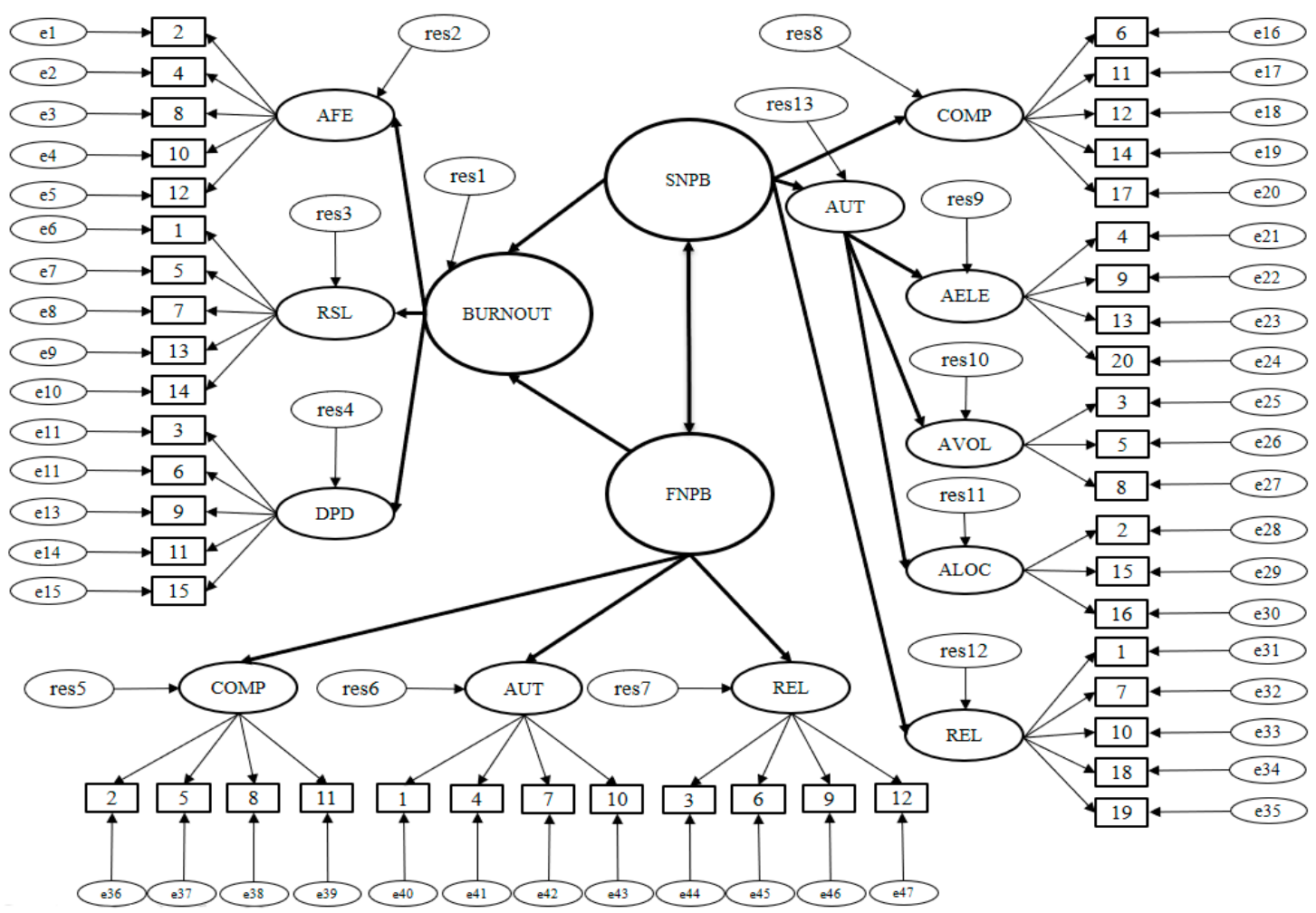

Figure 1. Hypothesized model with the structure relations between burnout, satisfaction, and frustration of basic psychological needs.

Table 4. Estimates for all items of the model.

\begin{tabular}{cccc}
\hline Items & $\boldsymbol{\lambda}$ & $\boldsymbol{\delta}$ & $\mathbf{R}^{\mathbf{2}}$ \\
\hline PEE 1 & 0.67 & 0.56 & 0.44 \\
PEE 2 & 0.57 & 0.68 & 0.32 \\
PEE 3 & 0.79 & 0.38 & 0.62 \\
PEE 4 & 0.73 & 0.47 & 0.53 \\
PEE 5 & 0.65 & 0.58 & 0.42 \\
RSA 1 & 0.63 & 0.61 & 0.39 \\
RSA 2 & 0.76 & 0.43 & 0.57 \\
RSA 3 & 0.66 & 0.55 & 0.45 \\
RSA 4 & 0.45 & 0.80 & 0.20 \\
RSA 5 & 0.53 & 0.72 & 0.28 \\
D 1 & 0.59 & 0.66 & 0.34 \\
D 2 & 0.69 & 0.53 & 0.47 \\
D 3 & 0.78 & 0.40 & 0.60 \\
D 4 & 0.61 & 0.63 & 0.37 \\
D 5 & 0.56 & 0.69 & 0.31 \\
\hline COM 1 & 0.64 & 0.60 & 0.40 \\
COM 2 & 0.71 & 0.50 & 0.50 \\
COM 3 & 0.66 & 0.57 & 0.43 \\
COM 4 & 0.77 & 0.41 & 0.59 \\
COM 5 & 0.82 & 0.33 & 0.67 \\
ACho 1 & 0.51 & 0.74 & 0.26 \\
ACho 2 & 0.71 & 0.50 & 0.50 \\
ACho 3 & 0.82 & 0.33 & 0.67 \\
ACho 4 & 0.76 & 0.43 & 0.57 \\
AVol 1 & 0.82 & 0.33 & 0.67 \\
\hline
\end{tabular}


Table 4. Cont.

\begin{tabular}{cccc}
\hline Items & $\boldsymbol{\lambda}$ & $\boldsymbol{\delta}$ & $\mathbf{R}^{\mathbf{2}}$ \\
\hline AVol 2 & 0.34 & 0.89 & 0.11 \\
AVol 3 & 0.61 & 0.63 & 0.37 \\
ALoc 1 & 0.71 & 0.50 & 0.50 \\
ALoc 2 & 0.83 & 0.32 & 0.68 \\
ALoc 3 & 0.87 & 0.25 & 0.75 \\
REL 1 & 0.66 & 0.57 & 0.43 \\
REL 2 & 0.39 & 0.85 & 0.15 \\
REL 3 & 0.73 & 0.47 & 0.53 \\
REL 4 & 0.82 & 0.33 & 0.67 \\
REL 5 & 0.84 & 0.30 & 0.70 \\
\hline COM 1 & 0.65 & 0.58 & 0.42 \\
COM 2 & 0.78 & 0.40 & 0.60 \\
COM 3 & 0.68 & 0.54 & 0.46 \\
COM 4 & 0.70 & 0.51 & 0.49 \\
AUT 1 & 0.49 & 0.76 & 0.24 \\
AUT 2 & 0.83 & 0.32 & 0.68 \\
AUT 3 & 0.72 & 0.49 & 0.51 \\
AUT 4 & 0.66 & 0.57 & 0.43 \\
REL 1 & 0.77 & 0.41 & 0.59 \\
REL 2 & 0.87 & 0.25 & 0.75 \\
REL 3 & 0.79 & 0.38 & 0.62 \\
REL 4 & 0.59 & 0.66 & 0.34 \\
\hline
\end{tabular}

Note. $\lambda$ : factorial loadings; $\delta$ : error variances; $R^{2}$ : percent of variance explained; PEE: physical and emotional exhaustion; RSA: reduced sense of accomplishment; D: sport devaluation; COM: competence; ACho: autonomy choice; AVol: autonomy volition; ALoc: autonomy internal perceived locus of causality; REL: relatedness; AUT: autonomy.

An invariance analysis was carried out to check that the general fit of the model was applicable, regardless of the sports modality practiced, individual or team. The analysis presented the following structure: Model 1 (configuration model) is a base model without restrictions in the estimation of parameters in the different groups on which the subsequent comparisons were made. In this type of model, the indicators that define the measurement structure have the same configuration among the selected groups. Model 2 specified, in addition to the factor structure, the equality or invariance of factor loads between groups, and model 3 added the correlations and factors variances.

The sample was divided between those athletes who competed in individual $(n=200)$ and collective $(n=439)$ sports. The differences in CFI values were also less than 0.01 for both model 2 $(\Delta \mathrm{CFI}=-0.001)$ and model $3(\Delta \mathrm{CFI}=-0.002)$ when compared to model 1 . Therefore, the factorial invariance between individual and collective sport modalities is stated. Table 5 shows the index obtained for invariance.

Table 5. Invariance of model in terms of sport type.

\begin{tabular}{cccccccccccccccc}
\hline Model & $\chi^{2}$ & df & $p$ & NNFI & CFI & RMSEA & $\begin{array}{c}\text { RMSEA } \\
\mathbf{9 0} \% \text { CI }\end{array}$ & $\begin{array}{c}\Delta \chi^{2} \\
\Delta g l\end{array}$ & $\Delta$ CFI \\
\hline $\begin{array}{c}\text { Sport } \\
\text { type }\end{array}$ & $\begin{array}{c}\text { 1. Configuration } \\
\text { model }\end{array}$ & 4640.11 & 2053 & $<0.01$ & 0.729 & 0.827 & 0.044 & $0.043-0.046$ & - & - \\
$\begin{array}{c}\text { 2. Invariant } \\
\text { loading factors } \\
\text { 3. Invariant } \\
\text { correlation factors }\end{array}$ & 4664.02 & 2063 & $<0.01$ & 0.727 & 0.826 & 0.044 & $0.043-0.046$ & 23.91 & 10 & -0.001 \\
\hline
\end{tabular}

Note. $\chi^{2}=$ chi squared; $\mathrm{df}=$ degrees of freedom; $p=p$-value; NNFI = Bentler-Bonett non-normed fit index; $\mathrm{CFI}=$ comparative fit index; RMSEA = root mean square error of approximation; $\mathrm{CI}=$ confidence interval; $\Delta=$ difference between values. 


\section{Discussion}

The present study was conducted to develop a model that established the relationships between burnout, satisfaction, and frustration of basic psychological needs (BPN). After checking the influence exerted by basic psychological needs on burnout, it can be stated that this research offers empirical support to the field of self-determination theory [3]. We highlight the importance of SDT in the etiology of burnout, which has been demonstrated empirically. In the same way, there is evidence to conclude that the autonomy in which three subscales are identified makes a positive contribution in the explanation of the relationships described above.

On a descriptive level, the highest mean of burnout dimension was for the reduced sense of accomplishment dimension, as occurs in other studies which the same instrument. In those studies, samples with similar sizes and with individual and team athletes were used [26,29]. Lonsdale, Hodge and Rose [30], affirmed that reduced sense of achievement is one of the dimensions that has more explanatory power over sports burnout syndrome.

For BPN satisfaction, the highest mean dimension score was for of autonomy volition. Similar results have been obtained in other studies that have used the same tool [23,31]. It should be noted that, according to the theory of basic psychological needs [3], autonomy seems to be the most important dimension, due to its high relationship with intrinsic motivation [10]. In addition, Reeve et al. [22] confirm how essential volition is, since it is the ability to feel free and act without pressure. In the regions where this questionnaire was administered, the athletes showed great freedom during their practice.

For BPN frustration, the highest mean was obtained in the competence dimension, as in Sicilia et al. [28]. However, the original version of the scale elaborated by Bartholomew et al. [6] presented higher mean scores for the autonomy. From a practical point of view, it has been observed in this study, as need for autonomy has been that the most satisfied among the athletes, so it makes sense that it is not the least frustrated dimension. As mentioned before, this is consistent with Ryan and Deci [3], considering this dimension the most relevant. Hodge, Lonsdale, and Ng [32], affirmed that competence is a dimension related to a reduced sense of accomplishment. Results, as previously seen, may be influenced by the high score in reduced sense of accomplishment. So it would be logical to think that athletes who have problems feeling satisfied with their sports performance have a reduced sense of personal accomplishment.

In the search to justify the origin of burnout syndrome in athletes, the BPN theory shows that the satisfaction of the same produces an increase in the state of subjective well-being and that the frustration of these needs is associated with a state of growing discomfort in the person [15], thus directly influencing the onset of burnout. Moreover, in line with results of the new findings on the nature of the constructs that form BPNT [18], the proposed model confirms that the satisfaction and frustration of needs presents a direct long-term effect on the burnout syndrome. The results describe independent behavior of satisfaction and frustration of basic psychological needs observed [21] and affirm the evidence of these needs has a different nature, and yet they are convergent, since they have a stable relationship.

Regarding the results obtained in the SEM model, it can be observed that the satisfaction of BPN had a negative influence on the syndrome of burnout. Therefore, as in other studies, it was affirmed that athletes who presented a greater satisfaction of these needs were those who had lower burnout indexes $[4,11,32]$. Regarding the frustration of BPN, the results showed a positive influence on athlete burnout, which confirmed what is stipulated in SDT and, therefore, affirmed that those athletes who presented a high frustration of BPN may, in turn, experience a greater degree of sports burnout $[5,8,16]$.

However, it could be seen in the present study that there were indications of the effect which exerted the frustration of BPN between BPN satisfaction and burnout. In addition, this effect was very similar to that found in the literature [9], and it should be noted that although the influence was not high, it must be taken into account when understanding the origin of athlete burnout. Therefore, these results present implications at a practical level in sport context allowing confirmation that the 
greater the satisfaction of basic psychological needs, the less the frustration of the same, which, in turn, causes the latter to exert less influence on burnout syndrome and so has lower effect. This affirmation means that both frustration and satisfaction of needs begin from the same theory, but both dimensions are different constructs, and it is needed to be treated like that in future researches [20].

About the overall fit of the model, some of the indexes did not exceed the acceptable adjustment criteria proposed by Schermelleh and Moosbrugger [33]. Specifically, the GFI and CFI indexes were slightly lower than 0.90 and 0.95 , respectively. On the contrary, $\chi^{2} / \mathrm{df}$, RMSEA and SMSR indexes did show acceptable adjustment values. Ruiz, Pardo and San Martin [34] affirm the more elements the model of structural equations integrates, the more difficult it is to obtain a good overall fit. As for the invariance of the model, compliance has been observed in the CFI differences proposed by Cheung and Rensvold [35]. They said that a model shows indicators of no invariance when differences in CFI values are greater than 0.01 . So the model has been shown to be invariant and valid for any type of sport, whether in individual or team modality.

One of the main limitations found carrying out this work is its transversal nature of this work. Several authors have reported changes in the different study variables over seasons or a temporary period in sports [33,36]. In addition, part of the data was collected by others during the competition season, so the psychological state has been changing. Therefore, it would be interesting to explore the changes produced in the levels of satisfaction and frustration of BPN throughout a sports season and how their influence on burnout varies.

For future research, it would be interesting to investigate the influence of BPN on other constructs such as motivation [30], in order to also examine the existing relationships with burnout and understand more of its origin. It could also be interesting to conduct a comparative study between a model that addresses satisfaction and frustration of needs both as the same concept and separate. In this way we could confirm the research of Longo et al. [19], in which satisfaction and frustration of psychological needs present a greater potential when treating them as different constructs. As seen above, the self-determination theory (SDT) helps to establish a solid base for explain the etiology of athlete burnout. The theory that has been proven presents a greater potential when taking into account the constructs unilaterally. That also turns out to offer a greater scientific contribution by knowing that three identified forms of autonomy influence the relationship between satisfaction of needs and this syndrome in the expected direction, as it had been raised in one of our hypotheses.

Another of the sub-theories that make up the SDT contemplates motivation [37], which also relates to this syndrome, an aspect to consider for future research. Cresswell and Eklund [11] affirm that in sport context the highest degree of intrinsic motivation are related to various positive states, such as high BPN satisfaction. On the other hand, states of demotivation have been associated as a possible source of various negative consequences, including burnout.

Finally, the main applications that this investigation may have should be highlighted. The results help with prevention and detection of burnout syndrome, especially at early ages. In addition, there are few theoretical models to explain athlete burnout with different sub-dimensions of autonomy taken into account, and BPN frustration uses to be treated as a unilateral concept.

In conclusion, it is likely that an athlete with a high self-determined motivation will have a higher BPNS, and therefore will be less prone to suffer athlete burnout. Also, the nature of the FBPN has a positive relationship with athlete burnout. Furthermore, FBPN and BPNS should be taken into account like different contructs for future researches, since they are constructs with different origins but simultaneous high potential, and treated together. It is also important to consider that there are three subscales identifing autonomy, that facilitate a more enriched understanding of the relationships between BPN theory and burnout.

Author Contributions: All authors contributed significantly to this article. F.P.P. made substantial contributions to the acquisition and to the interpretation of data, and drafting the manuscript. C.D.F. and C.A. revised the manuscript critically for final approval of the version to be published. Previously, they made substantial contributions to the conception or design of the work and interpretation of data. M.D.P.V.C. made significant 
contributions to the booklet design for the data collection, interpretation of the data, and drafting the manuscript. All authors have read and agreed to the published version of the manuscript.

Funding: This research was funded by the Ministry of Economy and Competitiveness of Spain under Grant PSI2014-56935-P.

Conflicts of Interest: The authors declare no conflict of interest.

\section{References}

1. Gustafsson, H.; DeFreese, J.D.; Madigan, D.J. Athlete Burnout: Review and Recommendations. Curr. Opin. Psychol. 2017, 16, 109-113. [CrossRef]

2. Raedeke, T.D.; Smith, A.L. Development and Preliminary Validation of an Athlete Burnout Measure. J. Sport Exerc. Psychol. 2001, 23, 281-306. [CrossRef] [PubMed]

3. Ryan, R.M.; Deci, E.L. Overview of Self-Determination Theory: An Organismic Dialectical Perspective. Handb. Self Determ. Res. 2002, 1, 3-33.

4. Li, C.; Wang, C.J.; Kee, Y.H. Burnout and Its Relations with Basic Psychological Needs and Motivation among Athletes: A Systematic Review and Meta-Analysis. Psychol. Sport Exerc. 2013, 14, 692-700. [CrossRef]

5. Perreault, S.; Gaudreau, P.; Lapointe, M.; Lacroix, C. Does it Take Three to Tango? Psychological Need Satisfaction and Athlete Burnout. Int. J. Sport Psychol. 2007, 38, 437-450.

6. Bartholomew, K.J.; Ntoumanis, N.; Ryan, R.M.; Thøgersen-Ntoumani, C. Psychological Need Thwarting in the Sport Context: Assessing the Darker Side of Athletic Experience. J. Sport Exerc. Psychol. 2011, 33, 75-102. [CrossRef] [PubMed]

7. Aguirre, G.; Tristán, R.; López-Walle, J.; Tomas, I.; Zamarripa, J. Estilos interepersonales del entrenador, frustración de las necesidades psicológicas básicas y el burnout: Un análisis longitudinal en futbolistas [Coach Interpersonal Styles, Frustration of Basic Psychological Needs and Burnout: A Longitudinal Analysis]. Retos 2016, 30, 132-137.

8. Jowett, G.E.; Hill, A.P.; Hall, H.K.; Curran, T. Perfectionism, Burnout and Engagement in Youth Sport: The Mediating Role of Basic Psychological Needs. Psychol. Sport Exerc. 2016, 24, 18-26. [CrossRef]

9. Mars, L.; Castillo, I.; López-Walle, J.; Balaguer, I. Estilo Controlador del entrenador, frustración de las necesidades y malestar en futbolistas futbolistas [Controlling Coach Style, Basic Psychological Need Thwarting and Ill-Being in Soccer Players]. Revista de Psicología del Deporte 2017, 26, 119-124.

10. Sarrazin, P.; Vallerand, R.; Guillet, E.; Pelletier, L.; Cury, F. Motivation and Dropout in Female Handballers: A 21-Month Prospective Study. Eur. J. Soc. Psychol. 2002, 32, 395-418. [CrossRef]

11. Cresswell, S.L.; Eklund, R.C. Motivation and Burnout in Professional Rugby Players. Res. Q. Exerc. Sport 2005, 76, 370-376. [CrossRef] [PubMed]

12. Gould, D.; Tuffey, S.; Udry, E.; Loehr, J. Burnout in Competitive Junior Tennis Players: I. A Quantitative Psychological Assessment. Sport Psychol. 1996, 10, 322-340. [CrossRef]

13. Cresswell, S.L.; Eklund, R.C. Athlete Burnout: A Longitudinal Qualitative Study. Sport Psychol. 2007, 21, 1-20. [CrossRef]

14. Cresswell, S.L.; Eklund, R.C. The Nature of Player Burnout in Rugby: Key Characteristics and Attributions. J. Appl. Sport Psychol. 2006, 18, 219-239. [CrossRef]

15. Ryan, R.M.; Deci, E.L. The Darker and Brighter Sides of Human Existence: Basic Psychological Needs as a Unifying Concept. Psychol. Inq. 2000, 11, 319-338. [CrossRef]

16. Quested, E.; Duda, J.L. Antecedents of Burnout among Elite Dancers: A Longitudinal Test of Basic Needs Theory. Psychol. Sport Exerc. 2011, 12, 159-167. [CrossRef]

17. Cheval, B.; Chalabaev, A.; Quested, E.; Courvoisier, D.S.; Sarrazin, P. How Perceived Autonomy Support and Controlling Coach Behaviors Are Related to Well-and Ill-Being in Elite Soccer Players: A Within-Person Changes and Between-Person Differences Analysis. Psychol. Sport Exerc. 2017, 28, 68-77. [CrossRef]

18. Neubauer, A.B.; Voss, A. The Structure of Need Fulfillment: Separating Need Satisfaction and Dissatisfaction on Between-and Within-Person Level. Eur. J. Psychol. Assess. 2016, 34, 220-228. [CrossRef]

19. Longo, Y.; Alcaraz-Ibáñez, M.; Sicilia, A. Evidence Supporting Need Satisfaction and Frustration as Two Distinguishable Constructs. Psicothema 2018, 30, 74-81. [CrossRef]

20. Sheldon, K.M. Integrating Behavioral-Motive and Experiential-Requirement Perspectives on Psychological Needs: A Two Process Model. Psychol. Rev. 2011, 118, 552-569. [CrossRef] 
21. Vansteenkiste, M.; Ryan, R.M. On Psychological Growth and Vulnerability: Basicpsychological Need Satisfaction and Need Frustration as a Unifying Principle. J. Psychother. Integr. 2013, 23, 263-280. [CrossRef]

22. Reeve, J.; Nix, G.; Hamm, D. Testing Models of the Experience of Self-Determination in Intrinsic Motivation and the Conundrum of Choice. J. Educ. Psychol. 2003, 95, 375-392. [CrossRef]

23. Ng, J.Y.; Lonsdale, C.; Hodge, K. The Basic Needs Satisfaction in Sport Scale (BNSSS): Instrument Development and Initial Validity Evidence. Psychol. Sport Exerc. 2011, 12, 257-264. [CrossRef]

24. Davis, L.; Stenling, A.; Gustafsson, H.; Appleby, R.; Davis, P. Reducing the Risk of Athlete Burnout: Psychosocial, Sociocultural, and Individual Considerations for Coaches. Int. J. Sports Sci. Coach. 2019, 14, 444-452. [CrossRef]

25. Eklund, R.C.; De Freese, J.D. Athlete Burnout. In Handbook of Sport Psychology; Tenenbaum, G., Eklund, R., Eds.; John Wiley \& Sons. Inc.: Hoboken, NJ, USA, 2020; pp. 1220-1240. [CrossRef]

26. Arce, C.; De Francisco, C.; Andrade, E.; Seoane, G.; Raedeke, T. Adaptation of the Athlete Burnout Questionnaire in a Spanish Sample of Athletes. Span. J. Psychol. 2012, 15, 1529-1536. [CrossRef] [PubMed]

27. De Francisco, C.; Parra, F.J.; Arce, C.; Vílchez, M.P. Preliminary Empirical Validation of the "Basic Needs Satisfaction in Sport Scale" with a Sample of Spanish Athletes. Front. Psychol. 2018, 9, 1-7. [CrossRef]

28. Sicilia, A.; Ferriz, R.; Sáenz-Álvarez, P. Validación española de la Escala de Frustración de las Necesidades Psicológicas (EFNP) en el ejercicio físico [Spanish Validation for Scale of Frustration of Psychological Needs in Physical Exercise]. Psicología Sociedad y Educación 2013, 5, 1-19.

29. Olivares, E.M.; Garcés de los Fayos, E.J.; Ortín, F.; De Francisco, C. Burnout's Prevalence through Two Measures and Its Relation with Sociodemographic's Variables. Univ. Psychol. 2018, 17, 33-41. [CrossRef]

30. Lonsdale, C.; Hodge, K.; Rose, E. Athlete Burnout in Elite Sport: A Self-Determination Perspective. J. Sports Sci. 2009, 27, 785-795. [CrossRef]

31. Parra, F.J.; Vílchez, M.P.; De Francisco, C. La satisfacción de las necesidades psicológicas básicas en función de la formación y experiencia del deportista: Características sociodeportivas. Revista de Psicología y Educación 2018, 13, 113-123. [CrossRef]

32. Hodge, K.; Lonsdale, C.; Ng, J.Y. Burnout in Elite Rugby: Relationships with Basic Psychological Needs Fulfilment. J. Sports Sci. 2008, 26, 835-844. [CrossRef] [PubMed]

33. Schermelleh-Engel, K.; Moosbrugger, H.; Müller, H. Evaluating the Fit of Structural Equation Models: Tests of Significance and Descriptive Goodness-of-Fit Measures. Methods Psychol. Res. Online 2003, 8, $23-74$.

34. Ruiz, M.A.; Pardo, A.; San Martín, R. Modelos de ecuaciones estructurales [Structural Equation Models]. Papeles del Psicólogo 2010, 31, 34-45.

35. Cheung, G.W.; Rensvold, R.B. Evaluating Goodness-of-Fit Indexes for Testing Measurement Invariance. Struct. Equ. Modeling 2002, 9, 233-255. [CrossRef]

36. DeFreese, J.D.; Smith, A.L. Athlete Social Support, Negative Social Interactions, and Psychological Health Across a Competitive Sport Season. J. Sport Exerc. Psychol. 2014, 36, 619-630. [CrossRef] [PubMed]

37. Ryan, R.M.; Deci, E.L. Intrinsic and Extrinsic Motivations: Classic Definitions and New Directions. Contemp. Educ. Psychol. 2000, 25, 54-67. [CrossRef]

(C) 2020 by the authors. Licensee MDPI, Basel, Switzerland. This article is an open access article distributed under the terms and conditions of the Creative Commons Attribution (CC BY) license (http://creativecommons.org/licenses/by/4.0/). 